\title{
Influências de Teorias Econômicas na Teoria Contábil: o caso da Função-Objetivo da Firma
}

\begin{abstract}
Resumo
Este ensaio tem por objetivo estabelecer a relação entre os preceitos teóricos contábeis que orientam os procedimentos de divulgação contábil para seus públicos de interesse, tanto internos quanto externos, com as duas principais correntes teóricas que tratam da função-objetivo da firma: a teoria dos Shareholders e a teoria dos Stakeholders. Na perspectiva da teoria dos Shareholders, a firma deve definir um objetivo único, que é o de maximizar a riqueza dos acionistas. No contexto da teoria dos Stakeholders, a firma deve estabelecer um objetivo múltiplo, qual seja o de atender aos interesses de todos os envolvidos com suas atividades. Discute-se em que medida teorias, padrões e práticas contábeis emanam de conceitos dos dois modelos, principalmente no que se refere à demanda pelos usuários de informações úteis e relevantes. Há predomínio da teoria dos Shareholders em influenciar preceitos contábeis que direcionam a divulgação de informações, embora já se discutam e se apresentem relatórios contábeis distintos, orientados para Stakeholders da firma, sem que tenha sido estabelecido conjunto de conceitos que os expliquem e justifiquem no âmbito da teoria Contábil. Adicionalmente, argumenta-se que ambas as correntes da teoria Econômica apontam, ao cabo e ao termo, para a mesma direção: buscar o bem-estar dos stakeholders da firma. A pesquisa contribui para a literatura contábil, no sentido de clarificar os impactos advindos dos dois modelos econômicos que tratam da função-objetivo da firma na evolução da teoria Contábil, ainda não captados diretamente na discussão dos fundamentos da teoria Contábil.
\end{abstract}

Palavras-chave: Teorias e Práticas Contábeis. Função-Objetivo da Firma. Teoria dos Shareholders. Teoria dos Stakeholders.

\begin{abstract}
Lineker Costa Passos
Mestrando em Administração e Controladoria na Universidade Federal do Ceará (UFC) e Professor do Instituto Federal de Educação, Ciência e Tecnologia do Estado do Piauí (IFPI). Contato: Rod. PI 213, Km 21. Cocal-PI, CEP: 64235-000 E-mail: linekerpassos@gmail.com
\end{abstract}

\section{Aline Nogueira Bezerra Mestranda em Administração e Controladoria na Universidade Federal do Ceará (UFC) e Analista Administrativo no Departamento Nacional de Produção Mineral. Contato: Rua Dr. José Lourenço,n. ${ }^{\circ}$ 905. Meireles. Fortaleza-CE, CEP: $60115-280$ \\ E-mail: 264.aline@gmail.com}

\section{Antonio Carlos Coelho}

Pós-doutor em Ciências Contábeis pela PPGCC-FEA-USP e Professor da Universidade Federal do Ceará (UFC). Contato: Av. da Universidade, n. $^{0} 2.431$. Benfica. Fortaleza-CE. CEP: $60020-180$ E-mail: accoelho47@gmail.com 


\section{Introdução}

A Contabilidade pode ser entendida como uma prática social que possui suas raízes na teoria Econômica, dado que sua função precípua é definida pelo ato de coleta, registro, acumulação e comunicação de eventos econômicos relativos à operação das firmas (Santos, Calíope \& Coelho, 2015), as quais, em conjunto, representam a essência da atividade econômica de uma sociedade (Hart, 1989).

Coase (1990) argumenta que a teoria do Sistema de Contabilidade é parte da teoria da Firma. Em outras palavras, é possível afirmar que a utilidade da Contabilidade, como ferramenta informacional, recebe manifestas influências de conceitos econômicos associados à firma e aos eventos associados a esta. Dentre esses conceitos, destaca-se a função-objetivo da firma, a qual, por meio de extensão conceitual adiante estabelecida, pode ter influenciado ou vir a influenciar o desenvolvimento de teorias contábeis vigentes e em evolução, o que também apresenta impactos na prática contábil, mormente no que tange à função informacional da contabilidade.

Tal atributo conceitual da firma tem sido alvo de discussão intensa no contexto de teorias da Firma, no que se refere às motivações que impulsionam e orientam decisões e ações de gestores na busca por determinado resultado ou à procura de direção e sentido para o funcionamento da empresa. Silveira, Yoshinaga e Borba (2005) destacam as duas principais vertentes que investigam explicações para tal direcionamento de decisões, quais sejam:

a) a condução dos negócios diligenciando maximizar a riqueza dos acionistas (teoria dos Shareholders);

b) o encaminhamento das atividades empresariais no sentido de equilibrar e satisfazer o interesse de todo público de interesse da organização (teoria dos Stakeholders).

Desse debate emergem duas correntes principais de pensamento que podem contribuir para o direcionamento da lógica informacional da Contabilidade: o principal, ou dominante, paradigma contábil aponta para priorizar informações direcionadas a acionistas, investidores e credores, nos mercados financeiros, cuja demanda tem foco em informações sobre o lucro, sintetizado na bottom line da DRE; já pesquisadores contábeis, em outra linha de pensamento, apresentam alternativas para focar em informações demandadas por todos os stakeholders, direcionando-se para a inclusão de informações de caráter social e ambiental no escopo das demonstrações contábeis.

Ressalta-se que o caráter maniqueísta do argumento acima se caracteriza por explícita adoção de uma dessas abordagens teóricas pelos pesquisadores contábeis. Nesse sentido, é possível segregar obras na literatura contábil nacional que adotam ou o enfoque informacional direcionado a shareholders - como exemplos, destacam-se as pesquisas de Coelho (2007) e Lopes (2001) e a obra de Lopes e Martins (2005) - ou o enfoque direcionado a stakeholders, destacando-se os estudos de Santana, Góis, De Luca e Vasconcelos (2015), Vellani e Ribeiro (2009) e Macêdo, Cordeiro, Pereira, Ribeiro, Torres e Lopes (2011).

Esse comportamento dos pesquisadores contábeis, bem como as práticas contábeis vigentes poderiam ser explicados e debatidos na ótica das teorias que discutem a função-objetivo da firma, a qual, imperativamente, pressiona a demanda por tal ou qual informação acerca das firmas, influenciando a posição de gestores e contadores na delineação das informações úteis aos usuários externos.

Até o final do século passado, a teoria Financeira, quase de forma mandatória, declarava e desenvolvia modelos nos quais as firmas tinham por objetivo precípuo e único a maximização da riqueza dos acionistas (shareholders), apresentando como referencial a função-objetivo clara e direta de que o valor da firma maximizado conduzia o sistema econômico à eficiência (Boaventura, Cardoso, Silva \& Silva, 2009).

Nesse sentido, Berle (1931) argumentava que todos os poderes concedidos para a gestão de uma empresa devem direcionar-se para o bem-estar dos shareholders. Essa abordagem se mostrou bastante ajustada ao comportamento efetivo das empresas, tanto que foi predominante nos últimos 150 anos (Sundaram \& Inkpen, 2004). 
Apoiada nas premissas associadas à teoria neoclássica da firma, a teoria dos Shareholders centra-se na figura do proprietário, seja individual, seja sócio ou acionista em suas diversas classes, tendo a firma como objetivo a maximização de seu próprio valor (Sunder, 2009), o que implica maximizar a riqueza dos sócios, proprietários dos recursos alocados como capital próprio das firmas.

Porém, é necessário destacar que, diferentemente da teoria dos Shareholders, a abordagem neoclássica da firma não apresenta em seu escopo separação entre propriedade e gestão, isto é, não há qualquer distinção entre as figuras do proprietário e do gestor, uma vez que ambos se confundem em papéis exercidos pelo mesmo agente na visão dessa abordagem (Sunder, 2014).

Neste estágio de ideias, sobre o entendimento em relação à firma, a Ciência Contábil elege como sua função principal, em um primeiro momento, o controle do patrimônio dos sócios, suporte básico conceitual que pode ser resumido na definição clássica de Contabilidade como "ciência que estuda os fenômenos patrimoniais" (Sá, 2002, p. 46), tal função é extensamente desenvolvida na importante escola italiana, baseada no conceito de "azienda", destacando a representação da riqueza dos proprietários (Sá, 1997).

$\mathrm{Na}$ escola americana, quando se desloca o foco da Contabilidade para a produção de demonstrações para os públicos de interesse na firma, muda-se o objeto (controle para informação), mas ainda predomina o fornecimento da informação do lucro como motivação principal para a divulgação contábil, ou seja, o principal alvo dos contadores e gestores é demonstrar o desempenho da empresa na direção do sócio, do proprietário.

Assim, seja do ponto de vista de colocações teóricas, seja no desenvolvimento das atividades contábeis, o direcionamento guarda similaridade com a função-objetivo guiada para shareholders.

De outra parte, dificuldades no funcionamento do mercado de ações, decorrentes de escândalos corporativos ocorridos em 2001 e 2002, ensejaram a que se reiniciasse debate sobre a finalidade das firmas como instrumento institucional fundamental para o funcionamento dos mercados (Sundaram \& Inkpen, 2004).

A partir de casos como Enron e Worldcom, que impactaram na eficiência do sistema econômico e financeiro mundial por comprometerem a riqueza de investidores e de outros fornecedores da empresa pela redução forçada de seus fluxos futuros de caixa esperados, passou-se a contestar a função-objetivo então dominante, como se ela não pudesse atender aos interesses e expectativas dos demais agentes econômicos envolvidos com a atividade econômica das firmas, em especial no que tange a consumidores e produtores intermediários.

Em especial, passou-se a argumentar que o objetivo da maximização da riqueza do acionista (Sundaram \& Inkpen, 2004) não conseguiria representar todo o complexo institucional dos mercados com eficiência e com justiça e equidade, em outras palavras, a função-objetivo de maximização da riqueza dos shareholders também deveria contemplar o atendimento do interesse dos demais interessados na operação da firma.

Como opção ao enfoque então predominante delineia-se proposição para abordagem alternativa sobre a função-objetivo da firma, que passou a ser conhecida como teoria dos Stakeholders, na qual se enfatiza que o objetivo corporativo deve ser estabelecido como uma função voltada para o equilíbrio e a satisfação dos interesses de todos os públicos envolvidos com a firma (Silveira et al., 2005).

Apesar de esta proposição datar do início do século XXI, as bases teóricas da teoria dos Stakeholders datam do final do século XX, inicialmente da obra de Freeman (1984), ao qual é creditado o pioneirismo em cogitar existir relevante ligação entre o conjunto de Stakeholders e a gestão estratégica das firmas (Sundaram \& Inkpen, 2004). Nessa ordem de ideias, a proposição original ainda apresentava características de alterar padrões comportamentais de gestão interna das firmas, sem maior preocupação com a governança, no sentido de proteção de recursos entregues à firma.

Apenas a partir dos escândalos contábil-financeiros comentados é que a teoria dos Stakeholders evolui para tentar explicar os relacionamentos da firma com seus públicos externos, incluindo a sociedade como um todo, instâncias governamentais não tributárias e a remuneração de todos os envolvidos com a firma. 
A academia contábil reage fundamentalmente com pesquisas e propostas que modifiquem o fulcro de informações contábeis, propondo a introdução de demonstrações contábeis menos financeiras (no sentido de atendimento ao interesse de acionistas) e mais sociais, instigando a que gestores passem a fornecer mais informações sobre aspectos referidos aos demais stakeholders na forma de relatórios ambientais, de responsabilidade social, de valor adicionado, em suma, balanços sociais (Dias, 2010; Iudícibus, Martins, \& Carvalho, 2005).

Ressalte-se que, em meados do século XX, Dodd (1932) apresentou esboço inicial da teoria dos Stakeholders, defendendo que a firma, como instituição econômica, tem um serviço social a cumprir.

Ambas as correntes, tanto a teoria dos Shareholders quanto a teoria dos Stakeholders, podem ser arroladas como cruciais para explicar a procedência e o conteúdo das teorias contábeis em discussão e o debate no meio acadêmico e regulatório dessa disciplina, principalmente no que tange à estrutura e teor das informações a serem ofertadas aos usuários da informação contábil, do ponto de vista dos usuários externos da informação contábil. Também é possível visualizar influências de tais aparatos conceituais nas teorias que tentam explicar a produção de informações gerenciais para fins de controle dos recursos e atividades da firma.

A teoria Contábil, por sua vez, busca, além do desenvolvimento de princípios fundamentais para a prática contábil, a compreensão de forças que moldam tal prática (Hendriksen \& Breda, 1999). Assim, tanto a teoria dos Shareholders quanto a teoria dos Stakeholders atuam como forças puramente teóricas que influenciam a prática contábil.

A questão se traduz em demarcar e estabelecer o fornecimento de informações para usuários externos, especulando sobre tais demandas, diferenciadas segundo o enfoque dos shareholders ou pela abordagem dos stakeholders. Acrescente-se ainda que a aplicação de tais preceitos envolve custos diferenciados, os quais apenas se justificariam pela utilidade gerada pelos relatórios divulgados para atender aos diversos interessados e envolvidos com o funcionamento da firma.

Lopes e Martins (2005) contribuem com a discussão, argumentando que a informação contábil teria como uma de suas principais intenções contribuir para a redução da assimetria informacional entre os gestores e o público externo da firma. Todavia, essa assimetria não se caracterizaria apenas pela quantidade, relevância, tempestividade, consistência e uniformidade, enfim, pelo atendimento a todas essas declaradas características fundamentais da informação contábil. A utilidade da informação contábil dependeria, também, de sua capacidade de comunicar o que seja efetivamente requerido pela função-objetivo dos usuários. Nesse sentido, também importaria, por exemplo, incorporar o atendimento a necessidades de usuários internos, representados, principalmente, pela figura dos gestores da firma.

Essa lógica de atender à demanda de usuários internos pressupõe que a função-objetivo das firmas conduz gestores a se apropriarem de informação contábil direcionada para o controle das ações de agentes internos, o que se denomina Contabilidade Gerencial ou Controladoria (Lopes, 2012).

Nesse contexto, Martins (2012) afirma que a Contabilidade nasceu voltada para os usuários internos, os quais foram perdendo espaço no seu processo normativo, tendo como reflexo o direcionamento desse processo quase que exclusivamente voltado para o usuário externo, mais especificamente os fornecedores de recursos financeiros. Tal direcionamento movido pela separação entre gestão e propriedade passou a ocorrer e se consolidar por todo o século XX.

A questão que se levanta neste ensaio, então, reside em propor um debate acerca da interação entre a teoria Contábil e a teoria Econômica, no que tange às duas correntes concorrentes que tentam explicar a função-objetivo da firma, compendiando os marcos teóricos das duas correntes de pensamento e explorando o esclarecimento do que propõe cada uma delas; além de sintetizar argumentos favoráveis e desfavoráveis em relação às teorias em debate.

Assim, esse ensaio tem por principal objetivo estabelecer pontos de correspondência entre os preceitos teóricos contábeis que orientam os procedimentos de divulgação contábil de fatos econômicos, financeiros e sociais da empresa para seus públicos de interesse, tanto internos quanto externos, com as correntes teóricas que tratam da função-objetivo da firma. Adicionalmente, constitui-se como objetivo secundário do estudo propor que ambas as correntes teóricas aqui tratadas convergem para uma mesma proposta: contribuir para o bem-estar de todos os envolvidos com a firma e suas atividades, sugerindo debates e questões alternativas. 
Convém destacar que, embora a teoria Contábil, no contexto atual, tenha sido e continue a ser influenciada por fenômenos como a harmonização internacional das normas contábeis, pressupõe-se que tais normas derivem de fundamentos teóricos suportados pela estrutura teórica contábil vigente, a qual, por sua vez, tem apoio subjacente em teorias econômicas, financeiras e administrativas, propondo-se neste ensaio enfocar tal intercâmbio a partir das teorias dos Shareholders e dos Stakeholders.

\section{Resenha das Teorias}

As firmas constituem o motor de funcionamento das economias capitalistas modernas (Hart, 1989) e também representam a essência da atividade econômica de uma sociedade. A acepção a respeito desse tipo de organização (as firmas), contudo, sofre influência tanto do contexto histórico quanto do paradigma teórico a que pertencem. Sua função-objetivo, portanto, tem variado conforme se desenham explicações conceituais para sua existência e forma.

Nesse sentido, até o século XIX, a firma era entendida como maximizadora monolítica do lucro, sendo modelo desenhado para explicar o equilíbrio em mercados para insumos e seus produtos, imperando nesse período a teoria Neoclássica da Firma (Sunder, 2014). Nessa abordagem teórica, a firma tinha como função-objetivo unicamente a maximização do lucro.

A partir dos anos 1920, com os primeiros questionamentos do modelo neoclássico, a teoria relacionada à firma desenvolve-se verdadeiramente, voltando seus estudos também para o seu funcionamento interno (Tigre, 2009).

Dentre os estudos seminais sobre a natureza da firma e sua relação com os agentes econômicos, destaca-se a obra de Berle e Means (1932), na qual esses autores documentaram a separação efetiva entre os controladores gerenciais e a propriedade acionária em grandes corporações nos Estados Unidos (Sunder, 2014).

Coase (1937), por sua vez, discute e sugere fundamentos que podem explicar o surgimento e a manutenção da organização econômica representada pela firma. Ele observou que a produção era coordenada pela firma e, não, pelo mercado, como decorrência da economia dos custos de transações, atribuindo-se a esse fato a razão para se estabelecer determinada firma. Esse mecanismo também seria responsável pelo delineamento interno da firma, no que tange a tamanho, organização societária e forma de funcionamento.

Além disso, Coase (1937) fez uma pergunta simples que ainda provoca longo debate: "por que a firma e, não, o mercado?".

Até então, os economistas tomavam a firma como a menor unidade de atividade econômica (Fontrodona \& Sison, 2006). A firma existiria, conforme Coase (1937), para permitir que o empresário coordenasse a produção, contrariando o paradigma neoclássico, pelo qual tal coordenação seria feita de forma eficiente apenas pelo mecanismo de preço operado no mercado. As discussões acima relatadas, embora refutem paradigmas neoclássicos, não aprofundam a discussão sobre a função-objetivo da firma.

Tanto a obra de Berle e Means (1932) quanto a obra de Coase (1937) apresentam como função-objetivo para a firma, amparados nos direitos de propriedade, a maximização da riqueza dos shareholders (Sundaram \& Inkpen, 2004), reforçando, nesse sentido, a teoria neoclássica da firma que sempre manteve a função-objetivo da firma centrada na figura do proprietário.

Berle (1931) já havia iniciado o debate sobre a função-objetivo da firma, a qual vem sendo, desde então, discutida predominantemente sob os dois prismas já antecipados: de um lado, o modelo voltado para maximizar a riqueza dos shareholders, tendo como um de seus precursores, precisamente, Berle (1931); do outro lado, desenvolve-se o modelo conceitual focado em apresentar a firma com a função-objetivo de atender ao interesse de todos os envolvidos com a organização, os stakeholders; para um de seus precursores, Dodd (1932), a firma deve ser vista como uma instituição econômica que tem um serviço social a cumprir.

Nos anos 1980, a função-objetivo da firma voltada para o interesse de todos os envolvidos ganha corpo com o desenvolvimento da teoria dos Stakeholders, creditado a Freeman (1984). 
Essa abordagem visualiza a firma como um organismo social, que interage com o ambiente em que atua, amparada na teoria sistêmica, devendo pautar suas estratégias com base na responsabilidade social (Freeman \& McVea, 2000). Cumpre destacar ainda que essa abordagem rejeita toda ideia de maximizar uma única função-objetivo como caminho para a gestão estratégica da firma ( (Freeman \& McVea, 2000).

\subsection{Teoria dos Shareholders}

A teoria dos Shareholders ou teoria da Maximização da Riqueza dos Acionistas, como também é conhecida, tem suas raízes nas teorias de economia e finanças (Jensen, 2001). Nessa perspectiva, uma definição que melhor ilustra o valor de 200 anos de trabalhos em economia e finanças indica que o bem-estar social é maximizado quando todas as firmas na economia maximizam seu valor total (Jensen, 2001). Esse argumento é reforçado pela maioria dos livros de Administração Financeira, conforme Brealey, Myers e Allen (2013), que afirmam que o administrador financeiro deve atuar no interesse dos proprietários, tendo por objetivo a maximização da riqueza destes.

A primazia da maximização da riqueza dos acionistas fundamenta-se nas teorias da Firma, precisamente na teoria Contratual da Firma (Silveira et al., 2005). Nessa perspectiva, duas obras seminais merecem destaque em tal discussão, a saber: os estudos de Berle e Means (1932) e de Coase (1937).

Berle e Means (1932) basearam-se nas premissas dos direitos de propriedade para argumentar que a gestão em prol do bem-estar dos shareholders é essencial para as decisões administrativas, uma vez que os shareholders são os proprietários da firma.

Por sua vez, Coase (1937) argumenta que as firmas correspondem a um nexo de contratos para minimizar custos de transação porventura presentes nos mercados, levando a existência da firma para algo que nada se relaciona à benevolência estatal ou ao atendimento de necessidades sociais, mas sendo voltada para maximizar a utilidade dos empreendedores.

Outras pesquisas vieram reforçar a ótica da teoria dos Shareholders - Macey (1991), Bainbridge (1993) e Smith (1998) -, enfatizando a primazia da maximização da riqueza dos acionistas, inclusive por meio de normas corporativas como função-objetivo da firma.

Sob a perspectiva das teorias da Firma, sobressaem-se as principais teses relacionadas a essa ótica no campo das teorias Econômicas, com o argumento de que deve caber aos proprietários dos recursos, sem cláusula de devolução, o direito sobre os lucros e a tomada de decisão no contexto da empresa (Silveira et al., 2005).

Dessa forma, se proprietários (shareholders) têm direito sobre os resíduos (lucros) dos recursos produzidos pela empresa, então a firma, ao maximizar seu valor, também maximizará a riqueza dos shareholders. Além desse argumento baseado no direito residual dos shareholders, também há a argumentação tradicional de que, como os shareholders são os stakeholders que carregam mais riscos e menos direitos legais em relação à firma, deve ser em favor deles que as decisões deverão ser tomadas (Fontrodona \& Sison, 2006; Silveira et al., 2005).

Além dessa situação, Silveira et al. (2005) tratam também de algumas questões que reforçam a proposição de primazia dos interesses dos shareholders, a saber: a hierarquia de recebimentos, o direito de acionar judicialmente a companhia; e os problemas de competitividade que a companhia possa estar enfrentando, situação essa em que todos os stakeholders podem deixar de renovar seus contratos, com exceção dos shareholders.

Em síntese, a teoria dos Shareholders diz que os gestores devem tomar todas as decisões de modo a aumentar o valor total de mercado da firma em longo prazo (Jensen, 2001). Assim, faz-se necessário abordar a relação entre gestores e shareholders sob a ótica da teoria da Agência.

Na teoria da Agência, essa relação assume a forma de contrato entre stakeholders e shareholders, de forma que os shareholders delegam poder de decisão para os stakeholders (gestores), criando as figuras do principal (shareholders), que delegam o poder, e do agente (stakeholders), aquele que toma as decisões em nome do principal (Fontrodona \& Sison, 2006). Convém destacar que a relação inversa também é possível, isto é, shareholders podem assumir o papel de agente, ao passo que stakeholders assumiriam o papel de principal na relação contratual. 
Sob a perspectiva dessa teoria, se os agentes se comprometem em atingir os objetivos fixados pelos shareholders, e o interesse desses é apenas econômico, então o objetivo da firma é maximizar a riqueza dos shareholders (Fontrodona \& Sison, 2006).

Ao maximizar a riqueza dos acionistas, o valor da empresa também estaria sendo maximizado na sua totalidade e, dessa forma, tal objetivo estaria favorecendo todos os envolvidos (stakeholders) com a firma (Sundaram \& Inkpen, 2004).

A firma cria valor social quando produz outputs ou conjunto de outputs que são avaliados por seus clientes superando o valor dos insumos consumidos no processo de produção (Jensen, 2001). Em outras palavras, o valor da firma corresponde ao valor de mercado desse fluxo de benefícios (ainda segundo Jensen, 2001).

Dentre os diversos argumentos coerentes com a teoria dos Shareholders, um que se destaca e reforça a perspectiva dessa teoria constitui-se na proposição de que a firma deve ter uma função-objetivo de valor único que corresponde à busca da maximização do valor da firma ou, em outras palavras, à maximização da riqueza dos shareholders (Jensen, 2001).

Para Jensen (2001), múltiplos objetivos não é objetivo em razão de ser logicamente impossível para a firma maximizar seu valor em mais de uma dimensão ao mesmo tempo, a menos que as dimensões sejam transformações de outra dimensão. Além disso, Sundaram e Inkpen (2004) argumentam que a teoria dos Shareholders não exclui a participação e os direitos de stakeholders.

Deste modo, analisando-se o valor da firma e levando-se em consideração a premissa de que esta proporcionará fluxos de caixa contínuos, Assaf e Lima (2014) apresentam a seguinte fórmula para determinar o valor da firma:

$$
V=F C_{i} / K
$$

Em que:

$V=$ Valor da Firma;

$F C_{i}=$ Fluxo de caixa operacional estimado para o i-ésimo período, com i tendendo ao infinito;

$K=$ Taxa que desconta a incerteza de consecução dos fluxos de caixa estimados.

No modelo, observa-se, entre as várias possibilidades, dois caminhos para que gestores maximizem o valor da firma e, consequentemente, a riqueza dos shareholders: maximizar o fluxo de caixa operacional, mantendo-se a taxa de incerteza constante; ou reduzir a taxa de incerteza, mantendo-se o fluxo de caixa operacional constante.

Ora, para ambos os caminhos será necessário para o gestor uma administração eficiente dos contratos dos demais interessados na companhia, ou seja, os gestores deverão também ater-se aos objetivos dos stakeholders. Portanto, ao utilizar os pressupostos da teoria dos Shareholders, também se estará buscando o bem-estar dos demais interessados (stakeholders).

No que se refere às críticas à teoria dos Shareholders, a mais óbvia refere-se à questão de que a maximização do valor da empresa pode suscitar implicações distributivas, isto é, os gerentes podem transferir valor para os shareholders a partir de outros stakeholders, em vez de criar valor e aumentar o tamanho da torta (valor da empresa) (Sundaram \& Inkpen, 2004). Além dessa crítica, Sundaram e Inkpen (2004) também destacam como crítica à teoria dos Shareholders as implicações de falhas contratuais com imposição de externalidades em relação a contratos diretos com terceiros, e que tais externalidades não se apresentam de forma única para os shareholders.

Cumpre destacar uma reflexão da teoria dos Shareholders sob a ótica da teoria contratual da firma. Segundo essa teoria, pode-se visualizar a firma como um conjunto de contratos entre agentes racionais (Sunder, 2014).

Ora, se a firma representa um nexo de contratos, então não há um único dono dela mesma, mas um conjunto de proprietários (Fontrodona \& Sison, 2006). Importa destacar a clara identificação dos proprietários dos fatores de produção (shareholders), mas não há razão para equiparar o proprietário do capital com o proprietário da firma (Fontrodona \& Sison, 2006). 
Em contraponto à teoria dos Shareholders está a teoria dos Stakeholders, que defende que a firma deve buscar equilibrar e satisfazer os interesses de todos os públicos envolvidos com a firma (Silveira et. al., 2005). Na seção seguinte, são abordados aspectos relevantes em relação a essa abordagem teórica.

\subsection{A Teoria dos Stakeholders}

A teoria dos Stakeholders tem suas origens em meados da década de 1980, tendo como foco inicial a publicação da obra de R. Edward Freeman, em 1984, denominada Strategic Management - A stakeholder Approach (Freeman \& Mcvea, 2000). Freeman visualizou a necessidade de um arcabouço conceitual diferente das raízes econômicas tradicionais e que fosse mais consistente com as mudanças no ambiente dos negócios da década de 1980, e, dessa forma, a teoria dos Stakeholders foi a responsável por esse desafio (Freeman \& McVea, 2000).

Embora a abordagem dos stakeholders tenha sido demonstrada na década de 1980, a ideia não foi inteiramente nova. No início da década de 1930, já havia forma ainda incipiente de esboço da teoria dos Stakeholders na obra de Dodd (1932), na qual se defende que a firma, como instituição econômica, tem um serviço social a cumprir. Vale ressaltar ainda que o uso do termo stakeholder cresceu a partir do trabalho pioneiro do Instituto de Pesquisa de Stanford (Stanford Research Institute - SRI) em 1960 (Freeman \& McVea, 2000).

Diferentemente da teoria dos Shareholders, que tem suas raízes nas teorias de economia e finanças, a teoria dos Stakeholders possui suas raízes principalmente no campo da sociologia, no comportamento organizacional e na política de interesses de grupos específicos (Silveira et al., 2005). Nesse sentido, um dos campos profícuos de pesquisa envolvendo o conceito de stakeholder refere-se à responsabilidade social corporativa (RSC) (Freeman \& McVea, 2000).

De acordo com a teoria dos Stakeholders, os gestores devem tomar suas decisões levando em consideração todos os públicos envolvidos com a firma (Jensen, 2001). A teoria dos Stakeholders tenta resolver a questão de qual grupo de stakeholders merece ou exige atenção dos gestores (Sundaram \& Inkpen, 2004). Nessa perspectiva, Freeman e McVea (2000) argumentam que os interesses dos stakeholders-chaves devem ser integrados à finalidade da firma, devendo os relacionamentos dos stakeholders ser geridos de forma coerente e estratégica.

É necessário destacar o que vem a designar o termo stakeholders. Segundo Jensen (2001), stakeholders pode ser definido como qualquer indivíduo ou grupo que afeta ou é afetado pelo alcance dos objetivos de uma firma, abrangendo não apenas reclamantes financeiros como os próprios shareholders, mas também empregados, clientes, comunidades e autoridades governamentais - em algumas interpretações, o termo stakeholders pode estar relacionado ao ambiente, terroristas, chantagistas e ladrões. Nessa linha de pensamento, Donaldson e Preston (1995) argumentam que há uma abrangência excessiva na identificação de stakeholders a partir da tendência de se adotar definições de stakeholders como "qualquer coisa que influencia ou é influenciada" pela firma (Freeman, 1984 como citado em Donaldson \& Preston, 1995). Essa definição coloca abertamente os stakeholders como atores que fazem parte do ambiente da empresa e que, de fato, podem ter algum impacto sobre as atividades da firma, mas que não têm interesse específico na própria firma (Donaldson \& Preston, 1995). Corroborando os autores, Silveira et al. (2005) apresentam algumas definições para stakeholders em dois polos distintos: em um polo, stakeholder é qualquer ator que tenha uma relação ou interesses com ou na firma; e no polo oposto, stakeholders primários são atores portadores de interesses em relação à firma, sem os quais esta não seria viável. 
A teoria dos Stakeholders pode ser, e tem sido, apresentada e usada de várias maneiras distintas, envolvendo metodologias muito diferentes (Donaldson \& Preston, 1995). Desse modo, Donaldson e Preston (1995) revelam três aspectos alternativos encontrados na literatura sobre essa abordagem, podendo ser caracterizada como descritiva ou empírica, instrumental e normativa. No aspecto descritivo, a teoria dos Stakeholders é utilizada para descrever e, algumas vezes, para explicar características e comportamentos específicos das firmas (Donaldson \& Preston, 1995). Quanto ao aspecto instrumental, a teoria dos Stakeholders, conjuntamente com os dados descritivos/empíricos, quando disponíveis, é utilizada para identificar as conexões, ou falta destas, entre a gestão dos stakeholders e os objetivos corporativos tradicionais (Donaldson \& Preston, 1995). Por fim, no aspecto normativo, a teoria dos Stakeholders é utilizada para interpretar a função da firma, incluindo a identificação de orientações morais e filosóficas para as operações e gestão das firmas (Donaldson \& Preston, 1995).

Nessa perspectiva, Freeman e McVea (2000) também observam que a teoria dos Stakeholders vem se desenvolvendo em quatro linhas distintas de pesquisa em gestão nos últimos 20 anos. Essas linhas são identificadas pelos autores como: planejamento empresarial; teoria de sistemas; responsabilidade social corporativa; e teoria Organizacional. Na linha de planejamento empresarial, emerge a concepção de que estratégias de sucesso são aquelas que envolvem o equilíbrio dos interesses de todos os stakeholders, em vez da maximização da posição de um único grupo em detrimento dos demais (Silveira et. al., 2005). Por sua vez, na linha da teoria de Sistemas e da teoria Organizacional dá-se ênfase a proposição de que as empresas são sistemas abertos que se relacionam com as diversas partes do ambiente, configurando-se necessária a elaboração de estratégias coletivas que beneficiariam o sistema como um todo (Silveira et. al., 2005). Finalmente, a linha de responsabilidade social corporativa não pode ser considerada um grupo teórico formalizado, mas uma coleção de abordagens de casos empresariais e de testes empíricos que enfatizam e demonstram a importância de se construir relacionamentos fortes e confiáveis, além de uma boa reputação com todos os stakeholders relacionados à firma (Silveira et. al., 2005).

Outros autores, como Hill e Jones (1992), também contribuíram para o desenvolvimento da teoria dos Stakeholders ao esboçarem relacionamento entre o conceito de stakeholders e a teoria da Agência. Segundo essa concepção, os gestores seriam os agentes de todos os stakeholders, e estes se diferenciariam entre si de acordo com seu poder e nível de interesse na firma, o que levaria a um constante desequilíbrio entre as forças envolvidas (Hill \& Jones, 1992).

O modelo teórico criado por Hill e Jones (1992) tem por foco as causas de conflitos entre gerentes e stakeholders após a emergência de condições de desequilíbrio. Essa abordagem teórica é similar, em muitos aspectos, à teoria da Agência, entretanto possui premissas relativas a processos de mercado que são substancialmente diferentes daquelas subjacentes à teoria da Agência; uma dessas premissas refere-se à eficiência de mercado, presente na teoria da Agência, a qual é relaxada no modelo de Hill e Jones (1992).

Em relação aos argumentos congruentes com a teoria dos Stakeholders, destaca-se o de Freeman (1984 como citado em Freeman \& McVea, 2000), que ressaltou a importância de uma abordagem teórica diferenciada em relação às teorias econômicas tradicionais e que fosse consistente com as mudanças do ambiente de negócios da década de 1980. Freeman e McVea (2000) destacam também que os gestores devem tomar as decisões empresariais respeitando o bem-estar dos stakeholders, em vez de tratá-los como meios para um fim empresarial. 
Em contrapartida aos argumentos acima, alguns críticos apresentam diversos argumentos relacionados à incoerência da teoria dos Stakeholders. Um argumento inicial que se apresenta é que essa teoria sugere a adoção de múltiplos objetivos pela firma, uma vez que as firmas devem equilibrar o interesse de todos os stakeholders. Nesse sentido, Sundaram e Inkpen (2004) argumentam que ter mais que uma função-objetivo tornará a governança difícil, se não impossível. Corroborando esses autores, Jensen (2001) argumenta que ter múltiplos objetivos não é objetivo. Outra crítica à teoria dos Stakeholders refere-se à liberdade dada aos executivos para a tomada de decisões, uma vez que não há um critério principal definido (Jensen, 2001). Jensen (2001), Sternberg (1999) e Sundaram e Inkpen (2004) destacam que as firmas que adotam a teoria dos Stakeholders terão dificuldade em competir por sua sobrevivência, principalmente em razão da falta de objetivos claros e únicos, a dificuldade de identificação dos stakeholders mais importantes para a empresa, a negação dos direitos de propriedade, entre outras razões (Silveira et. al., 2005).

Tanto a teoria dos Shareholders quanto a teoria dos Stakeholders possuem forte relação com a Contabilidade. A Contabilidade sofre influência de ambas as abordagens teóricas, no que tange às diferentes demandas por informações desses modelos teóricos.

\section{Influência na Formulação das Teorias Contábeis}

O exercício da contabilidade, ou seja, a prática e as normas contábeis, é fortemente influenciado pelo conceito econômico dominante da firma. A teoria Contábil, por seu turno, se pauta tanto pela abordagem dos shareholders quanto pelo enfoque dos stakeholders. Lopes (2012), por exemplo, afirma que não há uma única contabilidade capaz de atender a todos os interesses, uma vez que eles são muito distintos em função dos diferentes públicos interessados nas suas informações.

Sob a ótica da teoria Neoclássica, não haveria um papel para a contabilidade na operação da firma, uma vez que não haveria necessidade por informação em mercados perfeitos (Sunder, 2014), e, por premissa, a informação é livre e completa. Nesse caso, a função-objetivo da firma não dependeria do conhecimento sobre as operações da firma pelo usuário externo. Entretanto, isso não se poderia afirmar quanto a informações processadas internamente com foco exclusivo no controle, pois são motivadas tão somente por questões de gerência.

Contudo, pode-se buscar esclarecimento no enfoque dos shareholders - de maximização do valor da firma - para a configuração dos relatórios e das análises contábeis que enfatizam a divulgação do lucro (por meio da DRE); para a explicação dos movimentos do patrimônio líquido (DRA e DMPL); e para a explicitação dos fluxos de caixa na perspectiva econômica da capacidade de preservar a empresa (DFC); para os indicadores contábeis, que buscam sobremaneira avaliar o desempenho da empresa com medidas centradas na maior rentabilidade, maior liquidez e em estruturas que garantam a sobrevivência das empresas.

Já sob a perspectiva da teoria Contratual da Firma, a informação contábil passa a desempenhar papel decisivo na operação e avaliação da firma, atuando como uma das partes do mecanismo de execução dos contratos (Sunder, 2014), seja do ponto de vista do usuário externo, seja em se tratando de informações estritamente gerenciais. 
No contexto da teoria dos Shareholders, a contabilidade é desenhada para oferecer aos sócios e acionistas informações sobre o cumprimento dos contratos pelos agentes gestores, especialmente no que tange ao desempenho da firma, uma vez que aqueles dependem das contribuições e dos direitos dos contratos da firma para determinar seus próprios direitos (Sunder, 2014).

Ainda na perspectiva dessa abordagem, e sob a luz do argumento das teorias Econômicas da firma, em que os shareholders são os detentores dos direitos de controle e responsabilidade pela tomada de decisão na firma, caberia à contabilidade oferecer informações confiáveis e tempestivas que orientem suas decisões de investimento, sempre direcionadas a demonstrar o sentido de maximização da riqueza do investidor.

Outra questão relacionada à contabilidade e aos shareholders diz respeito aos custos exigidos pelo sistema de contabilidade, dado que as informações geradas por esse sistema (demonstrações contábeis) são compartilhadas com o público, em razão dos relatórios financeiros publicados corresponderem a bens públicos (Sunder, 2014). Mesmo assim, aceita-se tal dispêndio, dada a capacidade de avaliar desempenho por meio desses dados.

A geração de informações para usuários externos, principalmente shareholders, seria insuficiente para o alcance da função-objetivo da firma de maximização dos interesses dos sócios. Informações direcionadas àqueles que gerenciam a firma, dada a premissa de separação entre propriedade e gestão, já apontada por Berle e Means (1932), também teriam o caráter de prover informações sobre desempenho dos agentes, controlando principalmente custos de agência, de modo a garantir a remuneração dos acionistas (Martins, 2012). Pode-se, então, aduzir que sistemas de remuneração e compensação, sistemas de custos e orçamentários e outras ferramentas de avaliação de desempenho apoiaram-se na ideia subjacente da função-objetivo com foco nos shareholders.

Convém destacar que o arcabouço teórico atual da Contabilidade Gerencial identifica como foco desta a criação de valor para a firma pelo uso efetivo de recursos, utilizando-se de direcionadores de criação de valor para o consumidor, para o acionista e voltado à inovação organizacional (IFAC, 1998 como citado em Guerreiro, Cornachione, \& Soutes, 2011). Depreende-se dessa afirmação a influência tanto da teoria dos shareholders (ênfase na criação de valor para acionistas) quanto da teoria dos Stakeholders (ênfase na criação de valor para o cliente) na motivação da Contabilidade Gerencial.

Voltando-se ao contexto da teoria dos Stakeholders, pode-se entender que o principal impacto trazido por essa abordagem à prática e normatização contábil refere-se à criação de conjunto de informações sociais e ambientais referentes à firma. Iudícibus et. al. (2005) ponderam que a Contabilidade não pode privilegiar certos stakeholders, em prejuízo de outros, pois se estaria aumentando a assimetria informacional entre os diversos usuários da informação contábil.

Embora seja ainda elementar a produção de relatórios contábeis nessa linha de informações, pode-se citar a elevação da Demonstração de Valor Adicionado (DVA) à categoria de relatório obrigatório para algumas companhias, o que contribui para uma cultura empresarial embasada na transparência, (Dias, 2010).

A DVA é tida como instrumento de informações direcionadas a stakeholders porque apresenta a riqueza gerada pela firma (Cunha, Ribeiro, \& Santos, 2005), bem como sua distribuição aos diversos agentes em torno da operação da empresa, evidenciando o papel social da firma na comunidade em que está inserida (Cunha, Ribeiro, \& Santos, 2005).

Além disso, as firmas, ao final do século passado, intensificaram a adesão à ideia de Responsabilidade Social Corporativa, passando a divulgar, de forma voluntária, relatórios voltados a informar o balanço social de suas atividades. Assim, criou-se uma linha de pesquisa ativa na área contábil baseada na função-objetivo com foco em stakeholders, ainda sem um foco nítido do sentido das informações que não o direcionamento ético.

Nessa perspectiva, experiências como GRI e Relato Integrado alinham-se à visão de oferecer informações a múltiplos stakeholders. Reis, Cintra, Ribeiro e Dibbern (2015) tratam o relato integrado como uma promessa na qual se interligariam diversas informações relevantes, que facilitariam o entendimento da conexão entre os diversos grupos de informação. Destaca-se que essas experiências são objeto de linha de pesquisa ativa na área contábil. 
O surgimento da concepção de informação voltada aos interesses dos stakeholders alinha-se às fases de evolução da informação contábil (Iudícibus et. al., 2005). Em outras palavras, à medida que forem surgindo interessados diversos, a Contabilidade se transforma de sistema de informações e demonstrações contábeis simplificadas em um complexo sistema de informação e avaliação (Iudícibus et. al., 2005). Nessa visão, a teoria Contábil, em si, não teria sua própria função-objetivo, girando apenas em torno da produção de informações sobre a firma.

Dessa maneira, esboçam-se dois caminhos para a teoria Contábil: prestar informações voltadas para atender à função-objetivo de maximização da riqueza do acionista; ou voltar-se para a disponibilização de informações para todos os stakeholders relacionados à firma, incluindo os próprios shareholders.

No primeiro caso, a Contabilidade, apesar de reconhecidas possibilidades de vieses dos relatórios contábeis, a mercê de escolhas contábeis, já disponibiliza conjunto de relatórios direcionados aos shareholders. No segundo caso, apesar de alguns stakeholders (Governo, fornecedores) se beneficiarem com os relatórios direcionados aos shareholders, ainda não há relatórios suficientes para atender aos demais stakeholders da firma, embora já se depare com esforços de pesquisa nessa direção, tanto mundial como localmente.

Diferença fundamental entre as correntes teóricas discutidas refere-se à base conceitual ontológica do ser, considerada por essas; a corrente contábil voltada para produção de informações a stakeholders não considera base conceitual ontológica do ser, relacionada a por que produzir informações a todos os stakeholders; diferentemente da corrente contábil direcionada à produzir informações para shareholders, em que há explícita declaração de produzir informações úteis para a tomada de decisão dos agentes.

Tal contexto contribui para tornar difusa a corrente contábil que propõe a produção de informações direcionadas a todos os stakeholders, dado que não há identificação explícita do usuário da informação, bem como utilidade dessa para tal usuário.

Duas questões fundamentais explicitam o caráter ainda difuso da corrente contábil voltada para stakeholders: (i) todos os stakeholders demandam informações contábeis?; e (ii) a informação contábil tem utilidade para todos os stakeholders? As respostas a essas questões não são tratadas explicitamente pela corrente teórica direcionada a stakeholders.

\section{Conclusões}

Como exposto, a Contabilidade, no que tange a sua função informacional, tanto na ótica do usuário interno quanto no interesse do usuário externo, recebe influências manifestas das duas correntes teóricas que buscam explicar razões e motivações que orientam a gestão da firma.

No contexto da teoria dos Shareholders, a Contabilidade já disponibiliza relatórios direcionados a tais usuários, o que se evidencia pela estruturação das informações ofertadas e definidas nas principais estruturas conceituais em ambientes de economia desenvolvida ou em desenvolvimento.

Do ponto de vista da teoria dos Stakeholders, já se discutem e se apresentam relatórios contábeis orientados para os stakeholders da firma, abrangendo largo espectro de interesses nas linhas social e ambiental. Seu desenho, contudo, ainda não apresenta contornos nítidos, seja na direção, seja no formato. Tal especificação, ainda difusa, decorreria da baixa identificação de demanda por tais informações, seja pela alta dispersão de usuários, o que dificulta identificar sua utilidade, seja pelo próprio desenvolvimento dessa teoria.

Ademais, destaca-se a predominância da teoria dos shareholders em influenciar os preceitos contábeis que direcionam a divulgação de informações, argumento que se reforça pelo papel de tal vertente teórica em orientar a estrutura conceitual da Contabilidade nos principais padrões contábeis aplicados no mundo. 
Adicionalmente, embora as teorias dos Shareholders e dos Stakeholders apresentem argumentos distintos no que se referem à função-objetivo que a firma careça perseguir, em essência, ambas as abordagens resultarão na mesma formulação de seu objeto final, que é o bem-estar de todos os envolvidos com a firma.

Sundaram e Inkpen (2004) argumentam que o debate entre shareholders versus non share owning stakeholders está mal desenhado, uma vez que o objetivo de maximizar a riqueza dos shareholders pode ser manifestamente favorável aos demais stakeholders, dada a condição de organização social da firma.

Conforme exposto na equação de valor da firma, os gerentes, ao perseguirem a maximização da riqueza dos shareholders, também deverão ater-se aos objetivos dos demais stakeholders. Portanto, infere-se que não há um confronto ou oposição entre as abordagens, mas uma complementação, tendo em vista que a teoria dos Shareholders volta-se para a dimensão econômica, e a teoria dos Stakeholders volta-se para dimensões sociais e comportamentais.

\section{Referências}

Assaf, A., Neto, \& Lima, F. G. (2014). Fundamentos de administração financeira. São Paulo: Atlas.

Bainbridge, S. M. (1993). In defense of the shareholder wealth maximization norm: a reply to professor Green. Washington and Lee Law Review, 50, pp. 1423-1447.

Berle, A. A. (1931). Corporate powers as powers in trust. Harvard Law Review, 44(7), pp.1049-1074. doi: $10.2307 / 1331341$

Berle, A. A. \& Means, G. (1932). The modern corporate and private property. New York: McMillian.

Boaventura, J. M G.; Cardoso, F. R.; Silva, E. S. da \& Silva, R. S. da. (2009). Teoria dos stakeholders e teoria da firma: um estudo sobre a hierarquização das funções-objetivo em empresas brasileiras. Revista Brasileira de Gestão de Negócios, 11(32), pp. 289-307. doi: http://dx.doi.org/10.7819/rbgn.v11i32.378

Brealey, R. A.; Myers, S. C. \& Allen, F. (2013). Princípios de finanças corporativas (10ª ed.). Porto Alegre: AMGH.

Coase, R. H. (1937). The nature of the firm. Economica, 4(16), pp. 386-405.

Coase, R. H. (1990). Accounting and the theory of the firm. Journal of Accounting and Economics, 12(1), pp. 3-13. doi:10.1016/0165-4101(90)90038-6

Coelho, A. C. D. (2007). Qualidade informacional e conservadorismo nos resultados contábeis publicados no Brasil. Tese de doutorado, Universidade de São Paulo, São Paulo, SP, Brasil.

Cunha, J. V. A. D., Ribeiro, M. D. S., \& Santos, A. D. (2005). A demonstração do valor adicionado como instrumento de mensuração da distribuição da riqueza. Revista Contabilidade \& Finanças, 16(37), pp. 7-23. doi: http://dx.doi.org/10.1590/S1519-70772005000100001

Dias, J. M., Filho. (2010). A Contabilidade e a Ordem Social. Revista de Contabilidade da UFBA, 3(3), pp. 3-4.

Dodd, E. M. (1932). For whom are corporate managers trustees?. Harvard Law Review, 45(7), pp. 11451163. doi: $10.2307 / 1331920$

Donaldson, T. \& Preston, L. E. (1995). The stakeholder theory of the corporation:concepts, evidence, and implications. Academy of Management Review, 20(1), pp. 65-91.

Fontrodona, J. \& Sison, A. J. G. (2006). The nature of the firm, agency theory and shareholder theory: a critique from philosophical anthropology. Journal of Business Ethics, 66(1), pp. 33-42. doi: 10.1007/ s10551-006-9052-2

Freeman, R. E. (1984). Strategic management: a stakeholder approach. Boston: Pitman. 
Freeman, R. E., \& McVea, J. (2000). A stakeholder approach to strategic management. In M. Hitt, E. Freeman, \& J. Harrison (eds.). Handbook of strategic management. Oxford: Blackwell Publishing. Recuperado em 30 maio, 2015, de http://papers.ssrn.com/paper.taf?abstract_id=263511

Guerreiro, R.; Cornachione, E., Jr. \& Soutes, D. O. (2011). Empresas que se destacam pela qualidade das informações a seus usuários externos também se destacam pela utilização de artefatos modernos de contabilidade gerencial. Revista Contabilidade e Finanças, 22(55), pp. 88-113. doi: http://dx.doi. org/10.1590/S1519-70772011000100006.

Hart, O. (1989). An Economist's Perspective on the Theory of the Firm. Columbia Law Review, 89(7), pp. 1757-1774. doi: $10.2307 / 1122818$

Hendriksen, E. S. \& Breda, M. F. Van. (1999). Teoria da Contabilidade. São Paulo: Atlas.

Hill, C. W. L. \& Jones, T. M. (1992). Stakeholder-agency theory. Journal of Management Studies, 29(2), pp. 131-154. doi: 10.1111/j.1467-6486.1992.tb00657.x

Iudícibus, S. de, Martins, E., \& Carvalho, L. N. (2005). Contabilidade: aspectos relevantes da epopeia de sua evolução. Revista Contabilidade e Finanças, 16(38), pp. 7-19. http://dx.doi.org/10.1590/S151970772005000200002

Jensen, M. C. (2001). Value maximization, stakeholder theory, and the corporate objective function. Journal of Applied Corporate Finance, 14(3), pp. 8-21. doi: 10.1111/j.1745-6622.2001.tb00434.x

Lopes, A. B. (2001). A relevância da informação contábil para o mercado de capitais: o modelo de Ohlson aplicado à BOVESPA. Tese de doutorado, Universidade de São Paulo, São Paulo, SP, Brasil.

Lopes, A. B. (2012). A teoria dos contratos, Governança Corporativa e Contabilidade. In A. B. Lopes, \& S. de Iudícibus (Coord.). Teoria avançada da contabilidade (2a ed.). São Paulo: Atlas.

Lopes, A. B., \& Martins, E. (2005). Teoria da contabilidade. São Paulo: Atlas.

Macêdo, J.; Cordeiro, J.; Pereira, L.; Ribeiro, J., Filho; Torres, U. \& Lopes, J. (2011). Responsabilidade social e reputação corporativa: uma investigação sobre a percepção dos stakeholders numa concessionária de energia elétrica nordestina . Revista de Contabilidade e Organizações, 5(11), pp. 69-86. doi: http://dx.doi.org/10.11606/rco.v5i11.34786

Macey, J. (1991). An Economic Analysis of the Various Rationales for Making Shares the Exclusive Beneficiaries of Corporate Fiduciary Duties. Stetson Law Review, 21. pp. 23-40.

Martins, E. (2012). Contabilidade das Companhias Abertas no Brasil: Uma Agenda para o Futuro. In A. B. Lopes (Org.). Contabilidade e finanças no Brasil: estudos em homenagem ao professor Eliseu Martins. São Paulo: Atlas.

Reis, S. G.; Cintra, Y. C.; Ribeiro, M. S. \& Dibbern, B. R. S. (2015). Qualidade da divulgação socioambiental: um estudo sobre a acurácia das informações contábeis nos relatórios de sustentabilidade. Revista Contemporânea de Contabilidade, 12(25), pp. 67-94. http://dx.doi.org/10.5007/2175$-8069.2015 \mathrm{v} 12 \mathrm{n} 25 \mathrm{p} 67$

Sá, A. L. de. (1997). História geral e das doutrinas da contabilidade. São Paulo: Atlas.

Sá, A. L. de. (2002). Teoria da contabilidade (3a ed.). São Paulo: Atlas.

Santana, L. M. de, Góis, A. D., De Luca, M. M. M., \& de Vasconcelos, A. C. (2015). Relação entre disclosure socioambiental, práticas de governança corporativa e desempenho empresarial. Revista Organizações em Contexto-online, 11(21), pp. 49-72. doi: 10.15603/1982-8756

Santos, J. G. C., Calíope, T. S., \& Coelho, A. C. (2015). Teorias da Firma como fundamento para formulação de teorias contábeis. Revista de Educação e Pesquisa em Contabilidade (REPeC), 9(1), pp.101116. doi: http://dx.doi.org/10.17524/repec.v9i1.1182 
Silveira, A. Di M. da, Yoshinaga, C. E., \& Borba, P. da R. F. (2005). Crítica à teoria dos stakeholders como função-objetivo corporativa. REGE-Revista de Gestão, 12(1), pp. 33-42.

Smith, D. G. (1998). The Shareholder Primacy Norm. Journal of Corporate Law, 23(2), pp. 276-323.

Sternberg, E. (1999). The stakeholder concept: a mistaken doctrine. Foundation for Business Responsibilities, Issue Paper, (4). Recuperado em 22 julho, 2015 de < http://papers.ssrn.com/sol3/Papers. cfm?abstract_id $=263144>$

Sundaram, A. K., \& Inkpen, A. C. (2004). The corporate objective revisited. Organization Science, 15(3), pp. 350-363. http://dx.doi.org/10.1287/orsc.1040.0067

Sunder, S. (2009). Extensive income and value of the firm: who gets what?. CLPE Research Paper, 5(3).

Sunder, S. (2014). Teoria da contabilidade e do controle. São Paulo: Atlas.

Tigre, P. B. (2009). Paradigmas tecnológicos e teorias econômicas da firma. Revista Brasileira de Inovação, 4(1), pp. 187-223.

Vellani, C., \& Ribeiro, M. (2009). Sistema contábil para gestão da ecoeficiência empresarial. Revista Contabilidade \& Finanças, 20(49), pp. 25-43. doi: http://dx.doi.org/10.1590/S1519-70772009000100003. 